\title{
Impact of the High-Speed Flow of Powder Particles on the Structure of Polymer Materials and Metal-Polymer Composites
}

\author{
Yulia Usherenko \\ Scientific Laboratory of Powder \\ Materials \\ Riga Technical University \\ Riga, Latvia \\ osher_yu@mail.ru
}

\author{
Viktors Mironovs \\ Scientific Laboratory of Powder \\ Materials \\ Riga Technical University \\ Riga, Latvia \\ viktors.mironovs@gmail.com
}

\author{
Leonids Pakrastins \\ Institute of Structural Engineering \\ and Reconstruction \\ Riga Technical University \\ Riga, Latvia \\ Leonids.Pakrastins@rtu.lv
}

\begin{abstract}
The problem of protecting spacecraft from cosmic dust has recently come to the fore. There is still no enough data on the complex effect of short-term high-energy, dynamic loading on materials, including polymer materials and multilayer polymer-metal composites. The use of dynamic alloying in the super-deep penetration (SDP) mode by high-speed flows of powder particles allows assessing the effect on the material under dynamic action. Previous studies on steel and aluminum samples have shown a significant effect of high-speed flows of powder particles on the structure and properties of materials. As a result of a study of samples made of aliphatic polyurethane with steel reinforcement elements, it was found that there are traces of the penetration of high-speed particles into both metal and polymer layers. However, the number of flow elements detected in the polymeric part is significantly less than the number of elements in the metal reinforcing part. Thus, it is possible to assume that or the polymer material is a more effective barrier to the high-speed flow compared to the metal, or the "self-healing" effect is observed.
\end{abstract}

Keywords - cosmic dust, super-deep penetration, composites, powders, polymers, dynamic alloying

\section{INTRODUCTION}

The collision velocities of spacecraft with high-speed bodies and objects included in space debris range from $0.1 \mathrm{~km} \cdot \mathrm{s}^{-1}$ (lunar dust) to $70 \mathrm{~km} \cdot \mathrm{s}^{-1}$ (meteoric bodies) $\mathrm{km} \cdot \mathrm{s}^{-1}[1]$. At such collision velocities, intense energy release occurs in a limited volume of matter, accompanied by the formation of shock waves with subsequent mechanical destruction, melting, evaporation, and thermal ionization of the resulting vapors. Solid particles with transverse dimensions less than $1 \mathrm{~mm}$ can be considered as a factor constantly affecting spacecraft, characterized by their flux density [2].

Previous studies on steel and aluminum samples have shown a significant effect of high-speed flows of powder particles on the structure and properties of materials. [3-5].

The problem of protecting spacecraft from cosmic dust has recently come to the fore [6,7]. Thick-walled metal shells do not provide reliable protection for control systems. The bulky multilayer compositions are assumed to provide adequate protection when piercing protective shells with cosmic dust. However, there is still no enough data on the complex effect of short-term high-energy, dynamic loading on polymer materials and multilayer polymer-metal composites.

There is currently a wide variety of polymeric materials used as structural, thermal, and electrical insulating materials. The main advantages of polymers are high elasticity, low density, impact strength, specific electrical properties, high resistance to the effects of various active media, and the possibility of obtaining them with a given set of mechanical and physical properties. However, the number of calculated and experimental results on the study of dynamic loading of solid and porous polymer composites samples is minimal. Polymer composites are widely used in the aerospace industry, as safety and lightweight are essential factors. Polymer composites are used to manufacture small and large aircraft, including commercial, civil and military aircraft. The expanded use of polymer composites over metals in the aerospace sector is due to their high specific strength and stiffness combined with low density, resulting in weight savings. The benefits of weight reduction include reduced fuel consumption and 
emissions and increased speed, range, and maneuverability of aircraft [8-10].

For this reason, the development, testing, and implementation of a new generation of composite materials requires advanced studies. Currently, the aerospace industry needs to develop fundamentally new composite materials and tools for their diagnostics, which have a set of unique functional qualities and performance properties [11].

The use of dynamic alloying in the super-deep penetration (SDP) mode by high-speed flows of powder particles will allow assessing the effect on the material under dynamic action. Super-deep penetration (SDP) is a complex physical phenomenon, when in a split-second flow of powder particles with a fraction less than 100 microns, accelerated to speeds of $700-3000 \mathrm{~ms}^{-1}$, penetrates the solid metal body at depth in tens, hundreds $\mathrm{mm}$. Simultaneously, the high and ultra-high pressure (0.2$20 \mathrm{GPa}$ ), intensive deformation, local heating, and friction is occurred $[3-5,12]$.

\section{MATERIALS AND METHODS}

An aliphatic polyurethane plastic with a low viscosity was chosen as a model material. The density of the model material is $1.07 \mathrm{~g} / \mathrm{cm}^{3}$, the tensile strength is $21.8 \mathrm{MPa}$, and the hardness is 72 HSD. Polyurethanes are the most valuable and widely produced polymers in the industry. Polyurethanes contain a urethane group - NH-C(O)O-. They are characterized by the high modulus of elasticity, wear resistance, viscous coefficient of friction, vibration resistance, weather resistance, and resistance to oil and gasoline. Products made of polyurethane can be used when the temperature drops to $-60 \ldots-70^{\circ} \mathrm{C}$. Polyurethane fibers are low hygroscopic and have high chemical resistance. They are used for the manufacture of insulation, filter, and parachute fabrics. Today more than 3 million tons of polyurethane materials are processed every year. The promising nature of polyurethanes for the modern industry is since their properties substantially complement the possibilities of using other elastomers, rubbers, rubbers, etc. $[13,14]$. In terms of their structural and technological capabilities, polyurethanes are the most versatile polymer material. They find applications in aerospace, automotive, marine, railroad industries $[15,16]$.

Dynamic alloying in SDP mode was carried out in the following conditions [12]: ballistic explosive accelerator, average particles speed $1000 \mathrm{~ms}^{-1}$, exposure time - 400 microseconds, the material of samples: aliphatic polyurethane, quality structural carbon steel 10 (0.07$0.14 \%$ C, interstate standard GOST 1050-2013, DIN C10), the material of powder particles (strikers) - SiC powder (70\%), 63- 70 microns, Al powder (30\%), 10-70 microns.

The study of surface morphology and elemental composition was carried out on a certified high-resolution scanning electron microscope "Mira 3" "Tescan" with an $\mathrm{X}$-ray spectral microscope analyzer from "Oxford Instruments Analytical”. The error of the method, in this case, is 3 - 5 relative \%.
The microscope is equipped with detectors for secondary electrons (SE) and backscattered electrons (BSE), which allow the examination of samples in two modes. When taking samples in the secondary electron (SE) mode, a contrast in the image is created by the reflection of the electron beam from the sample surface. In the case of examination with a backscattered electron (BSE) detector, the contrast in the picture is created by the difference in the "averaged" atomic numbers. The type of detector used and other parameters are indicated on the information line at the bottom of each frame.

\section{RESULTS AND DISCUSSION}

As a result of a series of tests, it was found that experimental polymer samples (Fig. 1) and cast in metal tubes made of steel 10 (multilayer composites) (Fig. 2) withstand a dynamic load of $600-1000 \mathrm{~m} \cdot \mathrm{s}^{-1}$ without significant macro fracture.

The metal-reinforced multilayer composite option was considered. For the simulation, an aliphatic polyurethane plastic molded into steel 10 steel tubes with a sealed bottom was used. Dynamic processing was carried out from the side of the metal bottom. Of particular interest was the polymer-metal contact zone.

The use of samples placed in a metal tube made it possible to record the shock wave's propagation together with the outer metal shell. The pulsation of the initial metal cylinder along the samples' length is realized and, accordingly, a change in the diameter of the polyurethane sample in the cross-section along the axis (Fig. 2).

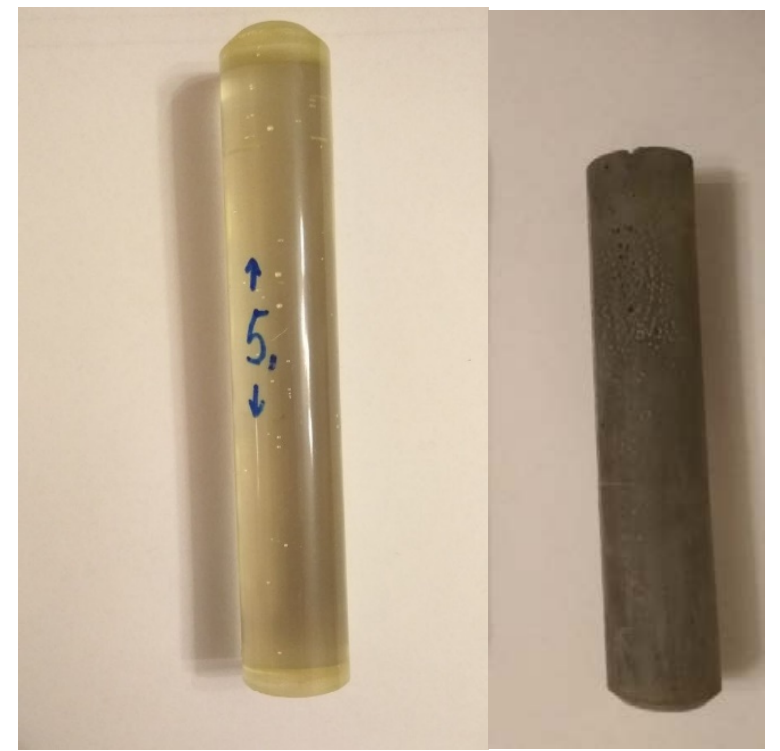

Fig 1. Experimental samples of polyurethane material before and after dynamic processing 


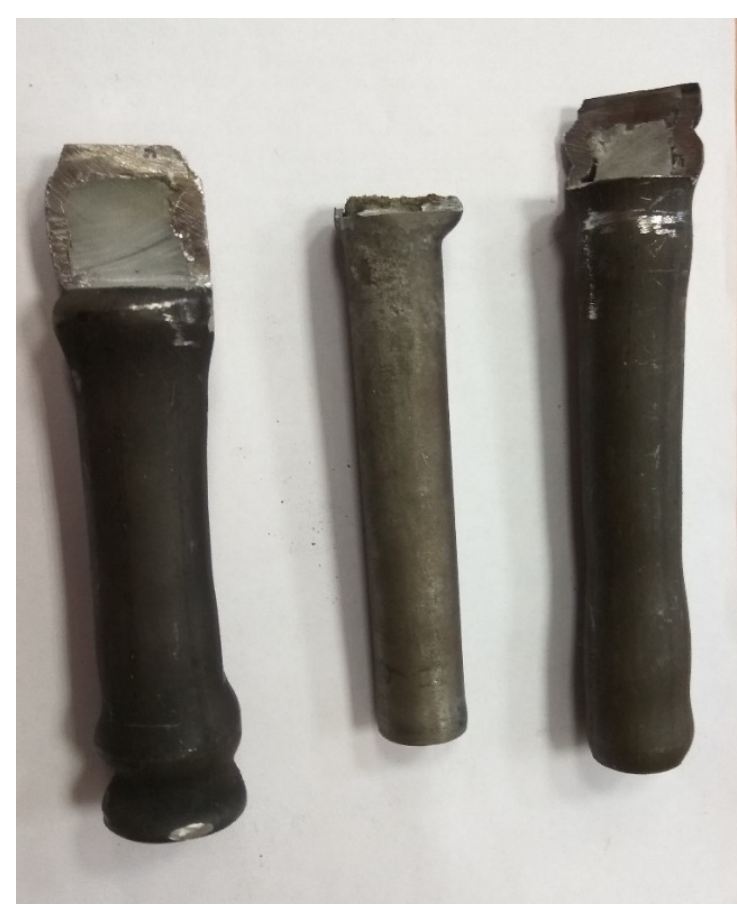

Fig. 2. Specimens made of polyurethane in a metal tube made of steel 10 after dynamic impact in the SDP mode.

Investigating the processed samples' structure made it possible to establish the superdeep penetration (SDP) process implementation. The channel elements in the steel shell were detected in the sample's metallic part (Fig. 3,4).

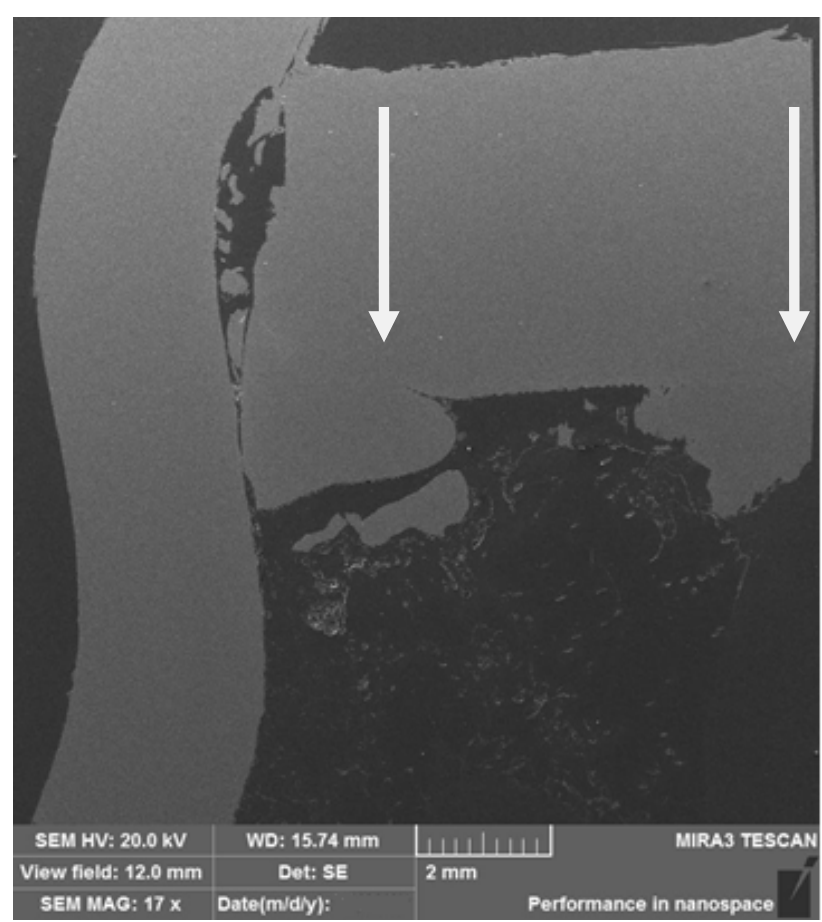

Fig. 3. Structure of the metal-polymer contact zone. The arrows show the direction of motion of the shock wave.

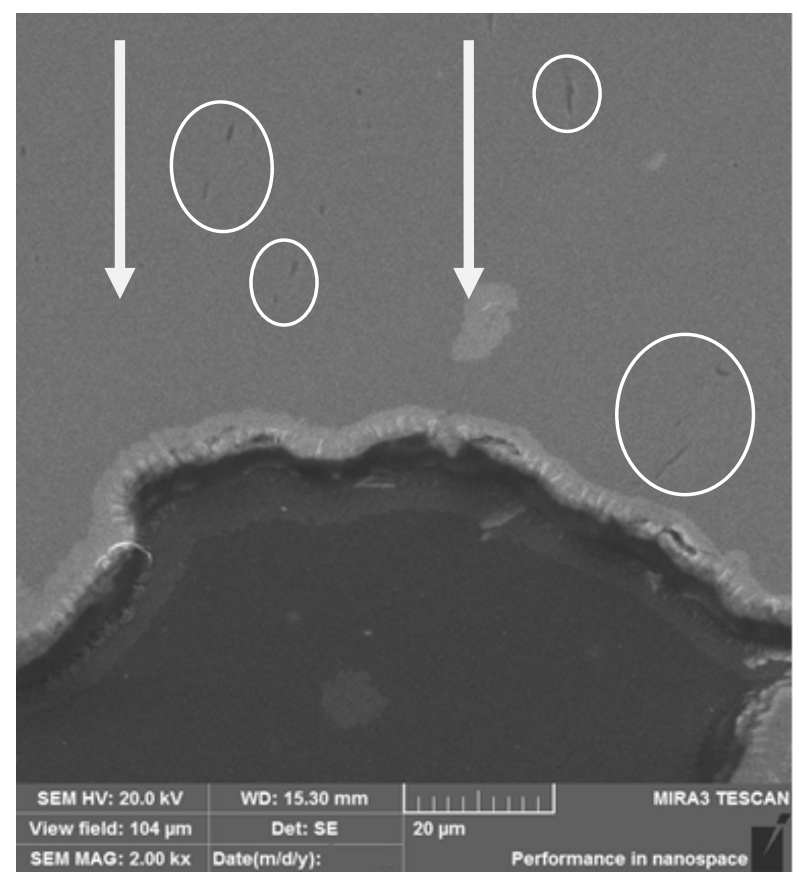

Fig. 4. Structure in the metal (top zone) -polymer (bottom zone) contact zone. The arrows show the direction of motion of the shock wave.

Ovals indicate the flow residues (channel elements)

Microanalysis of the channel elements of the metal part of the protective barrier also confirmed the presence of powder flow residues in the channels (Fig. 5 and Table 1). In the material of the steel shell, a zonal drift of aluminum and silicon was recorded. At the same time, iron, sulfur, and manganese were found in local zones. It can be assumed that during the analysis of steels, sulfur and manganese are recorded instead of isotopes (for example, $\left.{ }^{55} \mathrm{Fe}\right)$.

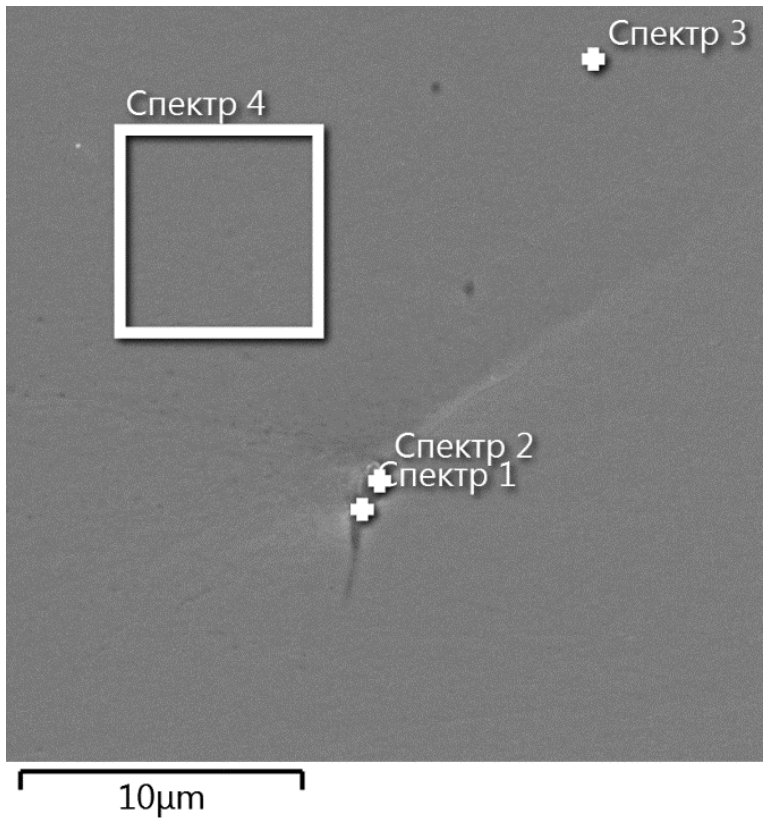

Fig. 5. Zone of microanalysis of the channel element (flow residue) of the steel part of the sample 
TABLE 1 MICROANALYSIS OF THE CHANNEL ELEMENT OF THE STEEL PART OF THE SAMPLE

\begin{tabular}{|r|r|r|r|r|r|}
\hline \multirow{2}{*}{$\begin{array}{c}\text { Spectrum } \\
\text { number }\end{array}$} & \multicolumn{5}{|c|}{ Content of elements, \%mass } \\
\cline { 2 - 6 } & $\mathrm{Al}$ & $\mathrm{Si}$ & $\mathrm{S}$ & $\mathrm{Mn}$ & $\mathrm{Fe}$ \\
\hline 1 & 1.57 & 0.22 & 17.50 & 32.48 & 48.23 \\
\hline 2 & 22.03 & 0.00 & 7.89 & 13.39 & 56.69 \\
\hline 3 & 0.00 & 0.31 & 8.79 & 15.46 & 75.43 \\
\hline 4 & 0.00 & 0.42 & 0.00 & 0.61 & 98.97 \\
\hline
\end{tabular}

The study of the polymer part structure showed the formation of the same structural element as in the metal part. Structural elements were identified with remnants of the powder flow material (Fig. 6) at a depth of 1-2 mm. It is confirmed by microanalysis results (Fig. 7 and Table 2). The proportion of aluminum in these zones was up to 75 mass. \%, silicon 20-100 mass.\%. Sulfur and iron are brought in by mass transfer from the steel shell.
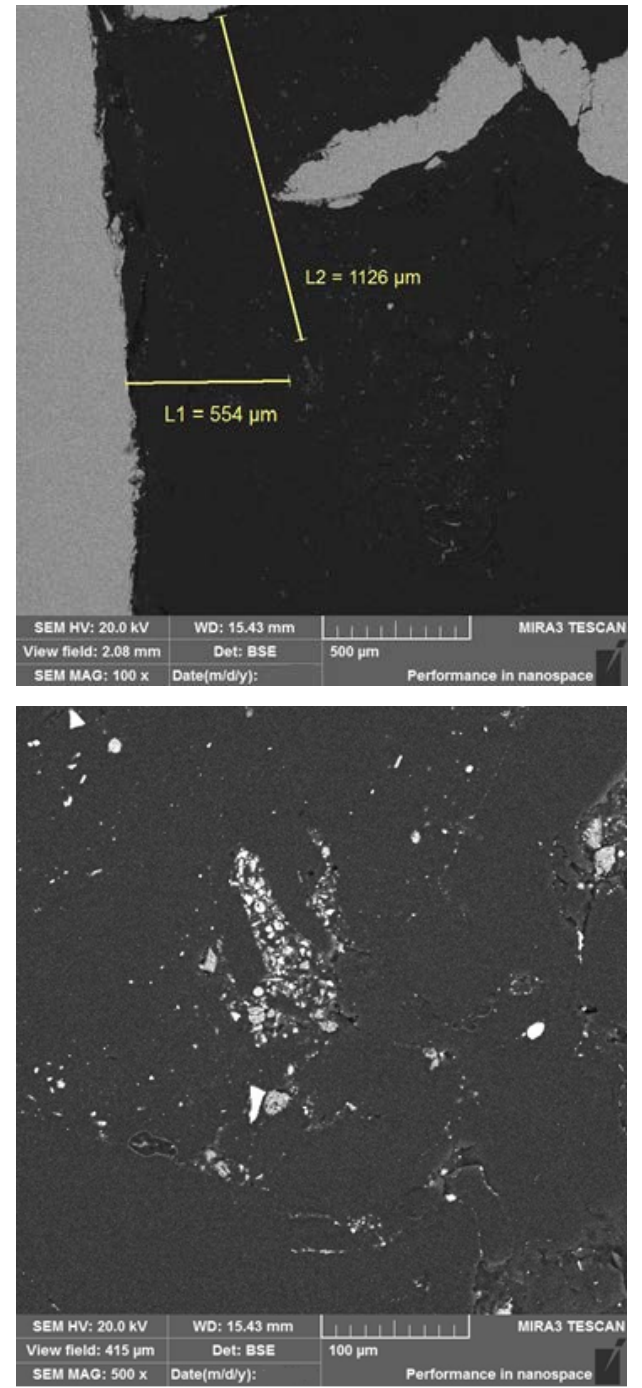

Fig. 6. The structural element of powder flow material residues in a polymer matrix.

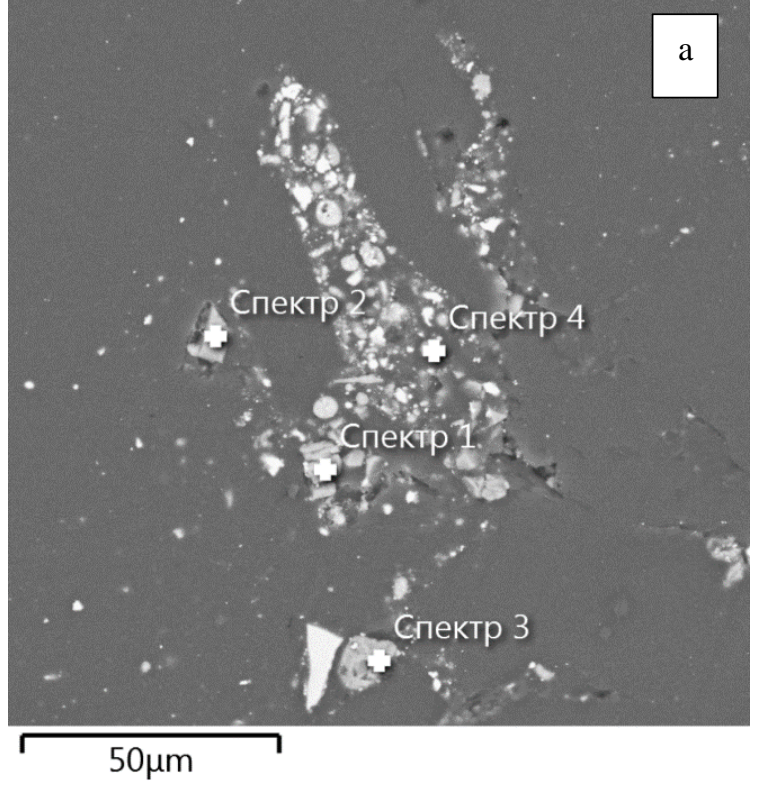

Si Kal

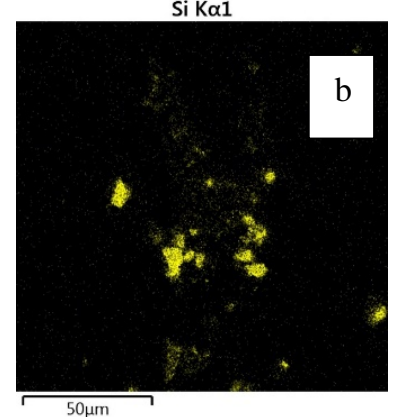

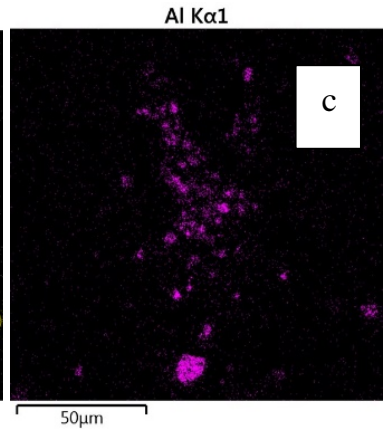

$50 \mu \mathrm{m}$
Fig. 7. Zone of microanalysis of a structural element from residues of powder flow material in a polymer matrix (a) and the distribution of traces of impactors from silicon carbide (b) and aluminum (c).

TABLE 2. MICROANALYSIS OF A STRUCTURAL ELEMENT FROM THE REMAINS OF THE POWDER FLOW MATERIAL IN A POLYMER MATRIX

\begin{tabular}{|r|r|r|r|r|r|}
\hline $\begin{array}{r}\text { Spectrum } \\
\text { number }\end{array}$ & \multicolumn{5}{|c|}{ Content of elements, \%mass } \\
\cline { 2 - 6 } & $\mathrm{Al}$ & $\mathrm{Si}$ & $\mathrm{S}$ & $\mathrm{Mn}$ & $\mathrm{Fe}$ \\
\hline 1 & 0.00 & 100.00 & 0.00 & 0.00 & 0.00 \\
\hline 2 & 0.00 & 99.33 & 0.00 & 0.00 & 0.67 \\
\hline 3 & 75.19 & 19.15 & 1.13 & 0.00 & 4.52 \\
\hline 4 & 75.59 & 20.21 & 1.97 & 0.00 & 2.23 \\
\hline
\end{tabular}

The study of the polymer part structure made it possible to establish the presence of remnants of the impactors of a high-speed powder flow. However, the number of flow elements detected in the polymeric part is significantly less than the number of elements in the metal reinforcing part (1 element in the polymeric part of the sample (fig. 6) versus a dozen of elements in the metal part (fig. 3,4). It can be assumed that the polymer part turned out to be a more effective material for decelerating high-speed particles in comparison with the metal one. Further studies, including the use of other types of polymeric materials, are of interest to refine this effect 


\section{CONCLUSIONS}

As a result of a series of studies of samples made of aliphatic polyurethane with steel reinforcement elements, it was found that there are traces of the penetration of highspeed particles into both metal and polymer layers.

However, the number of flow elements detected in the polymeric part is significantly less than the number of elements in the metal reinforcing part.

Thus, it is possible to assume that or the polymer material is a more effective barrier to the high-speed flow compared to the metal, or the "self-healing" effect is observed. Further research using other types of polymer materials is advisable.

\section{ACKNOWLEDGEMENTS}

This work has been supported by the European Regional Development Fund within the Activity 1.1.1.2 "Postdoctoral Research Aid" of the Specific Aid Objective 1.1.1 "To increase the research and innovative capacity of scientific institutions of Latvia and the ability to attract external financing, investing in human resources and infrastructure" of the Operational Programme "Growth and Employment” (No. 1.1.1.2/VIAA/2/18/335).

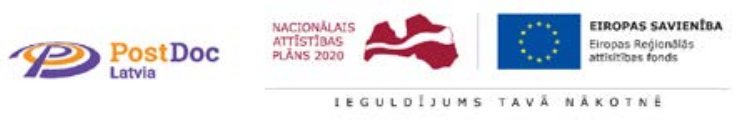

\section{REFERENCES}

[1] A. Belous, V. Saladukha, and S. Shvedau, "High velocity microparticles in space: influence mechanisms and mitigating effects of electromagnetic irradiation”, Springer, 2019.

[2] John M.C. Plane, "Cosmic Dust in the Earth's Atmosphere", Chemical Society Reviews, vol. 41, no.19, pp. 6507-6518, 2012.

[3] Y. Usherenko, S. Usherenko, and J. Yazdani, "High-energy method of transformation of casting metals and alloys to the composite materials”, Key Engineering Materials, vol. 721, pp. 290-294, 2016.

[4] Y.Usherenko, V. Mironovs, and S. Usherenko, “Analysis of the effects of dynamic alloying on the structure of aluminium and its alloys”, Solid State Phenomena, vol. 320, pp. 8-13,2021.
[5] Y. Usherenko, V. Mironovs, S. Usherenko, O. Reut, and V. Lapkovskis, "Properties of aluminium and its alloys under the effect of dynamic alloying”, IOP Conference Series: Materials Science and Engineering, to be published.

[6] A. Fletcher and S. Close, "Particle-in-Cell Simulations of an RF Emission Mechanism Associated with Hypervelocity Impact Plasmas”, Physics of Plasmas, vol. 24, no.5, pp. 053102-1-7, 2017.

[7] A. Nuttall and S. Close, "A thermodynamic analysis of hypervelocity impacts on metals”, International Journal of Impact Engineering, vol. 144, pp. 103645, 2020.

[8] R. Wang, S. Zheng, and Y. Zheng, "Polymer Matrix Composites and Technology”, Woodhead Publishing, 2011.

[9] M.K.Gupta and R.K. Srivastava, "Mechanical properties of hybrid fibers-reinforced polymer composite: A review”, Polymer-Plastics Technology and Engineering, vol. 55, pp. 626-642, 2016.

[10] M. R. Kessler, "Polymer matrix composites: A perspective for a special issue of polymer reviews”, Polymer Reviews, vol.52, no. 3, pp. 229-233, 2012.

[11] V.Ya Velichko and P.R. Chirkov,"Analysis of the prospects for the use of composite materials in the production of modern aircraft", Actual problems of aviation and cosmonautics, vol. 2, pp. 458-460, 2017 (In Russian) Я.В.Величко, and П.Р.Чирков, “Анализ перспектив применения композиционных материалов при производстве современных летательных аппаратов”, Актуальные проблемы авиации и космонавтики, vol. 2, nо. 13, pp. 458-460, 2017.

[12] V. Lapkovskis, S. Usherenko, Y. Usherenko, V. Mironovs, and V. Gluschenkov, "Powder particle flow acceleration methods for simulation of interaction with materials used in spacecrafts", Agronomy Research, vol.17, no.6, pp. 2445-2454, 2019.

[13] M. Szycher, “Szycher's handbook of polyurethanes”, CRC press, 1999.

[14] D. A. Jesson and J. F Watts, "The interface and interphase in polymer matrix composites: Effect on mechanical properties and methods for identification”, Polymer Reviews, vol.52, no. 3, pp. 321-354, 2012.

[15] V. Jothi, A. Y.Adesina, M.M. Rahman, A. M. Kumar, and J.N. Ram, "Improved Adhesion and Corrosion Resistant Performance of Polyurethane Coatings on Anodized Mg Alloy for Aerospace Applications”, Journal of Materials Engineering and Performance, vol.29, no. 4, pp. 2586-2596, 2020.

[16] Jie Liu, Zhao Li, Lunwu Zhang, Jian Hou, Zhonghai Lu, Peiqing Zhang, Bin Wang, and Nan Jin, "Degradation behavior and mechanism of polyurethane coating for aerospace application under atmospheric conditions in South China Sea”, Progress in Organic Coatings, vol. 136 pp.105310, 2019. 